\title{
Long live the wasp: adult longevity in captive colonies of the eusocial paper wasp Polistes canadensis (L.)
}

Robin J Southon, Emily F Bell, Peter Graystock, Seirian Sumner

Insects have been used as an exemplary model in studying longevity, from extrinsic mortality pressures to intrinsic senescence. In the highly eusocial insects great degrees of variation in lifespan exist between morphological castes in relation to extreme divisions of labour, but of particular interest are the primitively eusocial insects. These species represent the ancestral beginnings of eusociality, in which castes are flexible and based on behaviour rather than morphology. Here we present data on the longevity of the primitively eusocial Neotropical paper wasp Polistes canadensis, in a captive setting removed of environmental hazards. Captive Polistes canadensishad an average lifespan of $193 \pm 10.5$ days, although this average is shorter than most bee and ant queens, one individual lived for 506 days in the lab - longer than most recorded wasps and bees. Natal colony variation in longevity does exist between $P$. canadensis colonies, possibly due to nutritional and genetic factors. This study provides a foundation for future investigations on the effects of intrinsic and extrinsic factors on longevity in primitively eusocial insects, as well as the relationship with natal group and cohort size. 
2 Long live the wasp: adult longevity in captive colonies of the eusocial paper 2 wasp

3 Polistes canadensis (L.).

4 Robin J. Southon ${ }^{1}$, Emily Bell ${ }^{1,2}$, Peter Graystock ${ }^{1}$ and Seirian Sumner ${ }^{1}$

$5 \quad{ }^{1}$ School of Biological Sciences, University of Bristol, 24 Tyndall Ave, Bristol, 7 BS8 1TQ, UK

${ }^{2}$ Institute of Zoology, Zoological Society of London, Regent's Park, London, 9 NW1 4RY 1011

7

8

9 Abstract

10 Insects have been used as an exemplary model in studying longevity, from extrinsic mortality

11 pressures to intrinsic senescence. In the highly eusocial insects great degrees of variation in lifespan

12 exist between morphological castes in relation to extreme divisions of labour, but of particular interest

13 are the primitively eusocial insects. These species represent the ancestral beginnings of eusociality, in

14 which castes are flexible and based on behaviour rather than morphology. Here we present data on

15 the longevity of the primitively eusocial Neotropical paper wasp Polistes canadensis, in a captive

16 setting removed of environmental hazards. Captive Polistes canadensis had an average lifespan of

$17193 \pm 10.5$ days, although this average is shorter than most bee and ant queens, one individual lived

18 for 506 days in the lab - longer than most recorded wasps and bees. Natal colony variation in

19 longevity does exist between $P$. canadensis colonies, possibly due to nutritional and genetic factors.

20 This study provides a foundation for future investigations on the effects of intrinsic and extrinsic factors

21 on longevity in primitively eusocial insects, as well as the relationship with natal group and cohort size. 
$\underline{\text { Introduction }}$

Death comes to all, yet many seemingly ordinary insects have evolved some of the most dramatic and extraordinary lifespans, delaying the call of death for remarkable periods (Finch, 1990). Variation in insect longevity spans from Ephemera simulans males that live as adults for just 1.6 days (Carey, 2002) to the ants Pogonomyrmex owyheei and Lasius niger whose queens can live up to 30 years (Porter et al., 1988; Hölldobler et al., 1990). Interestingly, eusocial insects such as ants, wasps, and bees feature heavily as examples of longlived insects, but great variation exists not only between these species but also within species and even among genotypes. We understand little about the roles of ecology, evolution, life-history, and environment in generating variation in longevity in social insects, largely due to the difficulty of disentangling intrinsic life-span (hence-forth referred to as longevity) from survival (the abiotic and biotic environment pressures i.e. extrinsic mortality) on individuals (Hölldobler \& Wilson, 1990; Keller, 1998; Keeler, 2014; Giraldo \& Traniello, 2014).

Eusocial insects are one of the most dominant, prolific, and diverse groups of organisms on the planet (Wilson, 1975). Much of this groups' success is attributed to the division of labour within the colony in the form of castes, with few or a single reproductive individual (queen), supported by tens to millions of nonreproductive individuals (workers) that forage, provision, and care for sibling brood (Crespi, 1993). Caste fate is primarily determined by environmental conditions, e.g. nutrition during larval development and occasionally genetic biasing (Oster \& Wilson, 1978; Hölldobler \& Wilson, 1990; Hughes et al., 2003). Within species variation in longevity can be pronounced between castes with queens living as much as 100 -fold longer than their related workers (e.g. general: Kramer \& Schaible, 2013; Lucas \& Keller, 2014; ants: Hölldobler \& Wilson, 1990;

\section{Keller \& Genoud, 1997; wasps: Ridley, 1993). This is a remarkable example of a how a single genome can} display plasticity in aging (Keller, 1998; Fjerdingstad \& Crozier, 2006; Keeler, 2014). Few individuals are selected to specialise in egg production and therefore colony survival is likely to be highly associated with and dependent on queen longevity (in the absence of reproductive succession, see (Bourke, 2007). As a result, 
specialised egg layers are frequently protected from extrinsic pressures such as predation, for example the long-lived queens of the Harvester ant (Pogonomyrmex owyheei) live deep within the nest where they are sheltered (Porter \& Jorgensen, 1981). Assuming there are costs associated with longevity (e.g. nutritional demands during larval development, development time), evolutionary theory would predict there would be selection for short lifespan in workers, and long-life span in queens, especially in highly eusocial species where colonies are large enough to support highly specialised, short-lived workers (Evans, 1958; Carey, 2001; De Loof, 2011; Ferguson-Gow et al., 2014). This has been shown to be the case with weaver ants in a protected lab environment whereby major workers (whom take on more risky tasks) have a shorter intrinsic lifespan than minor workers whom adopt less risky tasks (Chapuisat \& Keller, 2002). Level of social complexity appears to be an important predictor of longevity in the eusocial insects. Castes are unlikely to have been selected for such differential longevity in the primitively eusocial species, where colonies are small, each worker is valuable, and survival of workers may be highly variable depending on the type or frequency of task each individual performs (Strassmann, 1985).

Between species, individual longevity is often correlated with mature colony size as shown in several wasp (Vespa spp.) and ant (Myrmica, Leptothorax, Solenopsis, Cataglyphis) species (Matsuura \& Yamane, 1990; Schmid-Hempel, 1998). In ants, at the colony level, the first worker brood is often physically smaller with a shorter lifespan than those produced later in the colony cycle, such as nanitic workers of ants (Porter \& Tschinkel, 1986). It is hypothesised that this may be due to the increase in levels of nutrition available to brood as the colony grows (Oster \& Wilson, 1978; Porter \& Tschinkel, 1986). As the colony grows, the ratio of workers to larvae often increases, the larvae will then benefit from increased quality and quantity of food, which can result in longer adult life-spans (e.g. in honey bees Apis mellifera: Groot, 1953; Eischen, 1982). Conversely in the primitively eusocial paper wasp $P$. exclamans, Strassmann (1985) identified that late emerging workers survived shorter than early emerging workers in 1977 and 1978. This patterns was subsequently not repeated in 1979 and its cause was suggested to be due to extrinsic factors. 
Extrinsic factors such as parasitism, prey availability, and abiotic conditions can be powerful

71 determinants of survival to wild individuals (Gibo \& Metcalf, 1978; Strassman, 1979; Strassmann, 1981; Tibbetts

$72 \&$ Reeve, 2003). To date there have been no studies on how worker longevity varies with colony size in primitively

73 eusocial insects in the absence of such extrinsic factors. Based on the larval nutrition quality to adult longevity theory we predict the same patterns will occur as in the highly eusocial species, since workers emerging early in

75 the colony cycle are subject to low worker:larvae ratio and therefore low quality nutrition. Conversely, those emerging late in the colony cycle experience high worker:larvae ratio and thus high quality nutrition (Sumner et al., 2007). Additionally, there may be a genetic link to longevity whereby some colonies are more likely to produce long living individuals than others, potentially due to heritable differences in feeding/hunting propensity

79 (VanRaden \& Klaaskate, 1993; Herskind et al., 1996; Vollema \& Groen, 1996; Klebanov et al., 2001; Sebastiani et al., 2012; Gems \& Partridge, 2013). If colony effects are important we predict that variation in longevity will be greater between colonies than within colony, even in the face of group size variation. Finally, positive correlations between colony size and longevity may be due to social-behavioural and metabolic factors such as increased per capita work rate in small colonies (Karsai \& Wenzel, 1998).

Here we provide primary data on longevity of females in captive colonies of the predatory and primitively eusocial Neotropical Polistes canadensis paper wasp. Primitively eusocial species such as those of paper wasp genus Polistes, have been used to extensively study the evolution of eusociality, with their lack of morphological differences and plasticity in caste (Turillazzi \& West-Eberhard, 1996; although see Hunt, 2006).

88 Although some studies have addressed the survivorship and colony phenology of some Polistes species (e.g.

89 O’Donnell \& Jeanne, 1992b; Giannotti, 1997a; Clapperton \& Dymock, 1997), there remain few systematic

90 attempts to quantify longevity, and variation of, in this well-studied genus. Many tropical Polistinae such as

91 Polistes canadensis, although influenced by wet/dry seasonality in food abundance (and resulting colony

92 productivity), mate and have colonies of various life-stages throughout the year (Pickering, 1980; Clutton-

93 Brock, 1991). These study systems offer an excellent system for testing the influence of ecology, evolution and 
environment on longevity, in the absence of seasonal curtailment of longevity in temperate species. Studying insect lifespans in captivity, in the absence of predation and parasitism, is a valuable approach that allows us to quantify longevity in the absence of extrinsic mortality pressures (Chapuisat \& Keller, 2002). We assess how natal colony size correlates with longevity under laboratory conditions and follow this up by comparing longevity in experimentally manipulated group sizes. Understanding variation in longevity in these organisms provides an excellent foundation to explore similar questions in the higher-order social vertebrates (Carey, 2001).

\section{Methods}

Collection: We collected ten colonies of the paper wasp, Polistes canadensis from the Province of Colón in Republic of Panamá in August 2013 for transportation $\left(9^{\circ} 24^{\prime} 03^{\prime \prime} \mathrm{N} 79^{\circ} 52^{\prime} 11^{\prime \prime} \mathrm{W}\right)$. Adult wasps were captured with full nest carton containing brood (eggs, larvae, and pupae) during dusk. The nest cartons and wasps were transferred to individual containers $(15 \mathrm{~cm} \times 15 \mathrm{~cm} \times 15 \mathrm{~cm})$ with wire mesh ventilation. Colonies were then provided with sugar solution and water ad libitum during transfer to the United Kingdom in luggage kept at ambient temperature. Turnaround from capture to settled maintenance in the laboratory was 48 hours. To ensure no colony was heavily infected with entomopathogens from the field, a subset ( 5 individuals per colony) of cadavers were placed in isolated petri dishes to observe any resulting sporulation of any infecting fungal entomopathogens. The common fungal agent Aspergillus spp. sporulated from $10 \%$ of these cadavers. Aspergillius is an opportunistic and largely ubiquitous fungus, commonly regarded as non-lethal to social insects unless under extreme stress or ingested at unnaturally high concentrations (Bailey, 1981; Foley et al., 2014).

Maintenance: Once in the UK we housed nests in clear transparent acrylic containers $30 \mathrm{~cm} \times 33 \mathrm{~cm} \times 34$ $\mathrm{cm}$ each with two $525 \mathrm{~mm}$ perimeter ventilation ducts (Figure 1). The food provided consisted of liquid cane sugar and live wax moth larvae Achroia grisella, along with distilled water and nest-building materials (cardboard 
117 colonies to ensure equal food quality provided to the adults to prevent any longevity variability as a result of

118 adult nutrition (Johanowicz \& Mitchell, 2000; Harvey et al., 2012). In addition to food, in each nest-boxes we 119 provided plastic artificial planting in the form of a strip of $7 \mathrm{~cm} \times 7 \mathrm{~cm} \times 2.5 \mathrm{~cm}$ grass sp. and a $5 \mathrm{~cm} \times 5 \mathrm{~cm} \times 5 \mathrm{~cm}$

120 plastic Hedera sp. for environmental enhancement to provide shelter from female aggression for males (Polak,

121 2010). The nest boxes were cleaned regularly with distilled water without disturbing wasps or nest. Natural

122 conditions from the collection sites were mimicked with temperatures of $25 \pm 1^{\circ} \mathrm{C}, 70 \pm 5 \%$ relative humidity, and

123 a light cycle of $12 \mathrm{~h}$ light (12h dark).

Data collection: The colonies were surveyed three to four times a week and any dead adults found were

immediately removed from the nest box. Total deaths per colony/cohort were tallied on a weekly basis and this

126 recording method continued until all individuals deceased. Whilst newly laid eggs were in the nest for the adults

127 to tend to, brood were eventually removed before pupation ensuring that only the original adult wasps captured

128 from the wild were monitored for longevity and the colony/cohort sizes never increased. This ensured all of the

129 adult wasps developed under natural nutritional conditions. Since all nests were collected from the same field

130 site at the same time, local environmental conditions for development are controlled for as best as possible,

131 though the colonies will differ from each other genetically.

132 As we do not know the eclosion date for each adult wasp, measures of longevity will be underestimates.

133 Hypothesis 1: Adult longevity of female $P$. canadensis will show some positive correlation with the size of the

134 natal group due to nutrition during development theory. Using the data generated from colonies M1-M7, we

135 were able to quantify variance in longevity between colonies to determine whether colony identity explains

136 variation in wasp longevity better than colony size. Using average survival per colony, correlations between initial

137 colony size upon setup in the UK were investigated.

138 Hypothesis 2: Group size will correlate positively with mean female longevity in $\boldsymbol{P}$. canadensis once the

139 influence of colony identity is controlled. Three colonies (M8, M9, M10) were monitored for a period of 3 
140 months, at which point their group sizes were of 28,23 and 23 workers respectively. Each colony was then split,

141 and randomly allocated between two new nest boxes lacking nest cartons, giving six new groups in total and

142 consisting of $18,13,12,8,8$ and 9 females. A non-natal male was also added to each the new colony nest boxes

143 so that females had the opportunity to mate. All cohorts then started to build nest cartons and lay eggs

144 suggesting mating may have occurred. The colonies were maintained as above with wasp deaths monitored

145 weekly for 220 days at which point all individuals were deceased.

146 Statistical analyses: Differences in adult survival where analysed using a Cox proportional hazards

147 regression model where colony was used as a factor. Where differences in survival were found, we conducted

148 pairwise comparisons between nests were made using Kaplan-Meier models with the Breslow $\chi^{2}$ statistic to

149 highlight specific patterns between the colonies. Pearson product-moment correlations were carried out to look

150 for patterns between colony size and average colony longevity. All analyses were carried out in SPSS Statistics

15121 (IBM, Armonk, NY, USA).

152 Results

153 Hypothesis 1: Adult longevity of female $P$. canadensis will show some positive correlation with the size of the 154 natal group.

155 Here we found that $57 \%$ of adult $P$. canadensis colonies maintained in the lab can survive beyond 365 days with

156 one individual living for 506 days, providing data on longevity for 143 wasps in total (Figure 2). On average wasps

157 lived for $193 \pm 10.5$ days with the oldest individual living for 506 days (Figure 2 and S1). Colony identity has a

158 significant influence on adult wasp longevity (Cox proportional hazard survival analyses Wald $=17.134$, d.f. $=6$,

$159 \mathrm{P}=0.009$ (Figure 2, Table S2). There was no correlation between colony size and the colonies average longevity

$160(r=0.06 \mathrm{n}=7 \mathrm{P}=0.89$; Figure $3 \mathrm{~A})$. Regular observations did not identify any behavioural differences between

161 colonies. All colonies built nests, maintained social cohesion, and regular egg laying was observed throughout. 
163 Hypothesis 2: Group size will correlate positively with mean female longevity in $\boldsymbol{P}$. canadensis once the 164 influence of colony identity is controlled.

165 Group sizes ranged from 9 (M5) to 34 (M7) wasps with average longevity within different nests ranging from

$166130 \pm 39.4$ days (in M5) up to 206 \pm 41.3 days (in M6). Comparing the mean adult longevity of colonies M1-M7

167 against their original size gives no clear association (Figure 3A). Colonies M8-M10 showed no difference in

168 survival prior to splitting (Wald $=4.016$, d.f. $=2, P=0.134$; Figure 4). However, after splitting into 6 cohorts of

169 variable size, females exhibited significantly different longevities (Wald $=12.544$, d.f. $=5, p=0.028$; Figure 5).

170 Cohorts from M9 (M9A \& M9B) and from M10 (M10A \& M10B) show no significant difference in adult

171 longevity within natal colony identity $\left(\chi^{2}=0.173, P=0.677 ; \chi^{2}=0.394, P=0.530\right.$ respectively; Table S3), cohorts

172 from colony M8 (M8A \& M8B) do differ from each other and are, incidentally, the 2 cohorts with the largest

173 size difference $\left(\chi^{2}=3.829, P=0.05\right.$; Figure 5). Group size shows a positive correlation with longevity $(r=0.84 \mathrm{n}$

$174=6 \mathrm{P}=0.038$; Figure 3B). Regular observations did not identify any behavioural differences between cohorts.

175 All cohorts built nests, maintained social cohesion, and regular egg laying was observed throughout.

\section{Discussion}

177 Here we show that with an average lifespan of 193 days, Polistes canadensis have some of the longest lifespans

178 of recorded wasps under laboratory conditions to date. The oldest wasp in our study lived for a staggering 506

179 days which is one of the longest living lab, assisted, or wild recorded wasp - and most recorded wild and assisted

180 bees, with the notable exception of assisted honeybee queens tending to live around live around 3000 days

181 (figure 6, Supplementary table S3). The natal group was a significant predictor of longevity with wasps living on

182 average between 260 days and 130 days depending on nest though the size of the natal groups had no

183 correlation with longevity. When natal groups were split in to varying cohort sizes the largest cohort lived the

184 longest and a correlation between longevity and cohort size was identified. We discuss the implications of this

185 data in the context of other species and ecology and evolution of eusociality. 
187 individuals were of queen, worker, or in a quiescence (Hunt, 2006) status/state. In the most general sense,

188 eusocial structure is based on behaviour rather than the physiological constraints observed in higher

189 Hymenopterans such as honey bees and many ants, which incidentally display the largest longevity disparities.

190 Though there are no directly comparable studies that use Polistes in a lab setting such as here, the lifespan

191 estimates on workers of wild or assisted Polistes species tend to live for approximately one month with the

192 longest average life span being 37 days in $P$. lanio and shortest life span being 14 days in P. exclamans (Miyano,

193 1980; Strassmann, 1985; Giannotti \& Machado, 1994b; Giannotti, 1997b, 2012; Gamboa, Greig \& Thom, 2002;

194 Torres, Gianotti \& Antonialli-Jr, 2013). although further empirical studies are needed to tease apart seasonal affects. In each case, the studies were carried out on wild Polistes colonies and so cannot to account for extrinsic mortality (Strassmann, 1985; Giannotti some wild Vespa spp. to 14.5 days in both lab maintained Vespula germanica and Vespula consobrina (Akre, 1982; Dazhi \& Yunzhen, 1989; Hölldobler \& Wilson, 1990).

On average there is a positive correlation between the maximum lifespan of eusocial queens and the among species tend to be due to extrinsic mortality (Keller, 1998). Here we cannot differentiate between egg 
specialisation to workers as that would ultimately reduce their direct fitness (Alexander, Noonnan \& Crespi,

210 1991). We may therefore expect to find similar lifespans in both egg layers and workers in $P$. canadensis,

211 However differences in lifespan are observed between helpers and egg layers in other Polistes species (figure 6).

212 These studies use wild species though and describe the extrinsic mortality unlike our study which had minimal 213 extrinsic pressures.

Colony identity was a clear predictor of wasp longevity. All colonies were collected at the same time

215 from the same field site, in which adults on all nests would have shared the same developmental and 216 environmental conditions. The potential causes for the effect of colony identity could be: 1) Genetic differences 217 between the colonies. Genetic influences on longevity have been found in a number of model species from 218 mammals to nematodes and insects (VanRaden \& Klaaskate, 1993; Herskind et al., 1996; Vollema \& Groen, 1996;

219 Klebanov et al., 2001; Sebastiani et al., 2012; Gems \& Partridge, 2013) and evidence for heritability of increased 220 longevity in the insect fruit fly and honey bees have been observed (Rinderer, Collins \& Brown, 1983; Luckinbill

$221 \&$ Clare, 1985) with some gene expression patterns being associated with longevity in queen honey bees (Corona et al., 2005). 2) Queen 'quality' which can be the result of extrinsic or intrinsic factors. Variation in fecundity of reproductive and dominance over other individuals in a colony is known as queen quality and this can vary 224 between queens (Harris \& Beggs, 1995; Liebig, Monnin \& Turillazzi, 2005; Holman, 2012). This queen quality variation can be inherited (Rinderer \& Sylvester, 1978; Corona et al., 2005) or driven by environmental factors (Hatch, Tarpy \& Fletcher, 1999; Tarpy et al., 2011). 3) Unobserved differences in extrinsic factors that the nests had experienced before collection. Since the colonies were not monitored for their entire history, there is the possibility that something affected each one differently in order to cause varying longevity within their workers. not correlate with wasp group size unless the size was manipulated. This suggests that the colony influences are 231 greater than those of group size and whilst an overall correlation between manipulated group size and longevity 232 was identified, only one out of three split colonies displayed this trend. This suggests that the explanation that 
233 larger colonies would produce longer lived workers due to enhanced nutrition during larval development is not 234 a major component.

To investigate the underlying variation in longevity in eusocial insects, data from captive colonies of a

236 range of eusocial insects is a useful tool and can help uncover variation in investment for longevity based on 237 extrinsic factors faced by a given species, individual, or caste (Chapuisat \& Keller, 2002). Predatory eusocial 238 insects such as wasps are underrepresented in the literature and while several excellent studies have been 239 identified, no studies have followed maintained Polistes in a protected lab environment. Here, for the first time 240 we quantify longevity of adult $P$. canadensis in the absence of extrinsic mortality and provide some support for 241 the link between group size and adult longevity but show that natal origin is a more powerful predictor. Our 242 results suggest predictions founded on previous research using higher eusocial species such as honeybees may 243 not be relevant to primitively eusocial species since their caste/fate is not fixed during development. A particular 244 challenge will be for future studies to also control for all of the described extrinsic and intrinsic factors such as 245 wild nest site condition and the presence of symbionts.

\section{Acknowledgements}

248 Thanks to Smithsonian Tropical Research Institute, particularly Jorge Morales and the staff at Galeta Point, and 249 field-assistant Daniel Fabbro. Research was funded by NERC studentship awarded to Emily Bell at IOZ, STRI Pre250 doctoral research fellowship and made possible following ANAM research permits SE/A-20-12 and SE/A-55-13. 251 Thanks to lan Warren \& Jacob Podesta for wasp husbandry.

\section{References}

253 Akre R. 1982. Economics and control of yellowjackets (Vespula, Dolichovespula). In: Biological control of crop 254 pests, stinging pests of man. 
Alexander R., Noonnan K., Crespi B. 1991. The evolution of eusociality. In: The biology of the naked mole rat. Princeton University Press, 34-59.

Archer M. 2012. Vespine Wasps of the World: Behaviour, Ecology \& Taxonomy of the Vespinae. Siri Scientific Press.

Bailey L. 1981. Honey Bee Pathology.

Bourke AFG. 2007. Kin Selection and the Evolutionary Theory of Aging. Annual Review of Ecology, Evolution, and Systematics 38:103-128.

Carey JR. 2001. Demographic mechanisms for the evolution of long life in social insects. Experimental Gerontology 36:713-722.

Carey J. 2002. Longevity minimalists: life table studies of two species of northern Michigan adult mayflies. Experimental gerontology 37:567-570.

Chapuisat M, Keller L. 2002. Division of labour influences the rate of ageing in weaver ant workers. Proceedings of the Royal Society B: Biological Sciences 269:909-13.

Clapperton BK, Dymock JJ. 1997. Growth and survival of colonies of the Asian paper wasp, Polistes chinensis antennalis (Hymenoptera: Vespidae), in New Zealand. New Zealand Journal of Zoology 24:9-15.

Clutton-Brock TH. 1991. The Evolution of Parental Care. Princeton University Press: Princeton, New Jersey.

Corona M, Hughes KA, Weaver DB, Robinson GE. 2005. Gene expression patterns associated with queen honey bee longevity. Mechanisms of ageing and development 126:1230-8.

Crespi BJ. 1993. The definition of eusociality. :109-115.

Dazhi D, Yunzhen W. 1989. A preliminary study on the biology of wasps Vespa velutina auraria Smith and Vespa tropica ducalis Smith. Zoological Research 10:162-163.

Eischen F. 1982. Length of life and dry weight of worker honeybees reared in colonies with different workerlarva ratios. Journal of Apicultural Research 21:19-25.

Evans HE. 1958. The evolution of social life in wasps. In: Proceedings of the 10th International Congress of Entomology. 449-457.

Ferguson-Gow H, Sumner S, Bourke AFG, Jones KE. 2014. Colony size predicts division of labour in attine ants. Proceedings of the Royal Society B: Biological Sciences 281.

Finch CE. 1990. Longevity, Senescence, and the Genome. The University of Chicago Press: USA.

Fjerdingstad E, Crozier R. 2006. The evolution of worker caste diversity in social insects. The American Naturalist 167:390-400. 
Foley K, Fazio G, Jensen AB, Hughes WOH. 2014. The distribution of Aspergillus spp. opportunistic parasites in hives and their pathogenicity to honey bees. Veterinary microbiology 169:203-10.

Gamboa GJ, Greig El, Thom MC. 2002. The comparative biology of two sympatric paper wasps, the native Polistes fuscatus and the invasive Polistes dominulus (Hymenoptera, Vespidae). Insectes Sociaux 49:4549.

Gems D, Partridge L. 2013. Genetics of longevity in model organisms: debates and paradigm shifts. Annual review of physiology 75:621-44.

Giannotti E. 1997a. Biology of the wasp Polistes (epicnemius) cinerascens Saussure (Hymenoptera: Vespidae). Anais da Sociedade Entomológica do Brasil 26:61-67.

Giannotti E. 1997b. Biology of the Wasp Polistes ( Epicnemius ) cinerascens Saussure ( Hymenoptera : Vespidae ). 26:61-67.

Giannotti E. 2012. Notes on the biology of Polistes simillimus Zikán (Hymenoptera, Vespidae). Bioikos 8:41-49.

Giannotti E, Machado V. 1994a. Colonial phenology of Polistes lanio lanio (Fabricius, 1775)(Hymenoptera, Vespidae). The Revista Brasileira de Entomologia 38:639-643.

Giannotti E, Machado V. 1994b. Longevity, life table and age polyethism in Polistes lanio lanio (Hymenoptera, Vespidae), a primitive eusocial wasp. Journal of Advanced Zoology 15:95-101.

Gibo DL, Metcalf RA. 1978. Early survival of Polistes apachus (Hymenoptera: Vespidae) colonies in California: a field study of an introduced species. The Canadian Entomologist 110:1339-1343.

Giraldo YM, Traniello JF a. 2014. Worker senescence and the sociobiology of aging in ants. Behavioral Ecology and Sociobiology 68:1901-1919.

Goldblatt JW, Fell R. 1987. Adult longevity of workers of the bumble bees Bombus fervidus (F.) and Bombus pennsylvanicus (De Geer) (Hymenoptera: Apidae). Canadian Journal of Zoology 65:2349-2353.

Groot A de. 1953. Protein and amino acid requirements of the honeybee (Apis mellifica L.). Physiologia Comparata et Oecologia 3:197-285.

Halcroft M, Haigh a. M, Spooner-Hart R. 2013. Ontogenic time and worker longevity in the Australian stingless bee, Austroplebeia australis. Insectes Sociaux 60:259-264.

Harris RJ, Beggs JR. 1995. Variation in the quality of Vespula vulgaris (L.) queens (Hymenoptera: Vespidae) and its significance in wasp population dynamics. New Zealand Journal of Zoology 22:131-142.

Harvey J a, Cloutier J, Visser B, Ellers J, Wäckers FL, Gols R. 2012. The effect of different dietary sugars and honey on longevity and fecundity in two hyperparasitoid wasps. Journal of insect physiology 58:816-23.

Haskins C, Haskins E. 1980. Notes on female and worker survivorship in the archaic ant genus Myrmecia. Insectes Sociaux 27:345-350. 
Hatch S, Tarpy DR, Fletcher DJC. 1999. Worker regulation of emergency queen rearing in honey bee colonies and the resultant variation in queen quality. Insectes Sociaux 46:372-377.

Herskind AM, McGue M, Holm N V., Sørensen TI a., Harvald B, Vaupel JW. 1996. The heritability of human longevity: A population-based study of 2872 Danish twin pairs born 1870-1900. Human Genetics 97:319323.

Hölldobler B, Wilson EO. 1990. The Ants. Harvard University Press, Cambridge, MA.

Holman L. 2012. Costs and constraints conspire to produce honest signaling: insights from an ant queen pheromone. Evolution 66:2094-2105.

Hughes WOH, Sumner S, Van Borm S, Boomsma JJ. 2003. Worker caste polymorphism has a genetic basis in Acromyrmex leaf-cutting ants. Proceedings of the National Academy of Sciences 100:9394-9397.

Hunt J. 2006. Evolution of castes in Polistes. Annales Zoologici Fennici:407-422.

Hurd CR, Jeanne RL, Nordheim E V. 2007. Temporal polyethism and worker specialization in the wasp, Vespula germanica. Journal of insect science 7:1-13.

Jeanne R. 1975. The adaptiveness of social wasp nest architecture. Quarterly Review of Biology 50:267-287.

Jemielity S, Chapuisat M, Parker JD, Keller L. 2005. Long live the queen: studying aging in social insects. Age 27:241-8.

Johanowicz D, Mitchell E. 2000. Effects of sweet alyssum flowers on the longevity of the parasitoid wasps Cotesia marginiventris (Hymenoptera: Braconidae) and Diadegma insulare (. Florida Entomologist 83:4147.

Karsai I, Wenzel J. 1998. Productivity, individual-level and colony-level flexibility, and organization of work as consequences of colony size. Proceedings of the National Academy of Sciences 95:8665-8669.

Keeler KH. 2014. Southwestern Association of Naturalists Fifteen Years of Colony Dynamics in Pogonomyrmex occidentalis, the Western Harvester Ant , in Western Nebraska. 38:286-289.

Keller L. 1998. Queen lifespan and colony characteristics in ants and termites. Insectes Sociaux 45:235-246.

Keller L, Genoud M. 1997. Extraordinary lifespans in ants : a test of evolutionary theories of ageing. Nature 389:3-5.

Klebanov S, Flurkey K, Roderick TH, Archer JR, Astle MC, Chen J, Harrison DE. 2001. Heritability of life span in mice and its implication for direct and indirect selection for longevity. :209-218.

Kramer BH, Schaible R. 2013. Colony size explains the lifespan differences between queens and workers in eusocial Hymenoptera. Biological Journal of the Linnean Society 109:710-724. 
Liebig J, Monnin T, Turillazzi S. 2005. Direct assessment of queen quality and lack of worker suppression in a paper wasp. Proceedings of the Royal Society B: Biological Sciences 272:1339-44.

De Loof A. 2011. Longevity and aging in insects: Is reproduction costly; cheap; beneficial or irrelevant? A critical evaluation of the "trade-off" concept. Journal of insect physiology 57:1-11.

Lucas ER, Keller L. 2014. Ageing and somatic maintenance in social insects. Current Opinion in Insect Science 5:31-36.

Luckinbill LS, Clare MJ. 1985. Selection for Increased Longevity in Drosophila melanogaster. 55:9-18.

Matsuura M. 1971. Nest foundation by the female wasps of the genus Vespa (Hymenoptera, Vespidae). Japanese journal of entomology 39:99-105.

Matsuura M, Yamane S. 1990. Biology of the vespine wasps. Springer Verlag.

Michener C. 1969. Comparative social behavior of bees. Annual review of entomology 14:299-342.

Miyano S. 1980. Life tables of colonies and workers in a paper wasp, Polistes chinensis antennalis, in central Japan (Hymenoptera: Vespidae). Researches on Population Ecology 22:69-88.

O'Donnell S, Jeanne R. 1992a. The effects of colony characteristics on life span and foraging behavior of individual wasps (Polybia occidentalis, Hymenoptera: Vespidae). Insectes Sociaux 80:73-80.

O’Donnell S, Jeanne RL. 1992b. Lifelong patterns of forager behaviour in a tropical swarm-founding wasp: effects of specialization and activity level on longevity. Animal Behaviour 44:1021-1027.

Oster G, Wilson E. 1978. Caste and ecology in the social insects.

Page Jr RE, Peng C. 2001. Aging and development in social insects with emphasis on the honey bee, Apis mellifera L. Experimental gerontology 36:695-711.

Pamilo P. 1991. Life span of queens in the ant Formica exsecta. Insectes Sociaux 119:111-119.

Pardi L. 1948. Dominance order in Polistes wasps. Physiological Zoology 21:1-13.

Polak M. 2010. Landmark Territoriality in the Neotropical Paper Wasps Polistes canadensis (L.) and P. carnifex (F.) (Hymenoptera: Vespidae). Ethology 95:278-290.

Porter SD, Jorgensen CD. 1981. Foragers of the harvester ant, Pogonomyrmex owyheei: a disposable caste? Behavioral Ecology and Sociobiology 9:247-256.

Porter SD, Jorgensen CD. 1988. Longevity of Harvester Ant Colonies in Southern Idaho. Journal of Range Management 41:104.

Porter SD, Tschinkel WWR. 1986. Adaptive value of nanitic workers in newly founded red imported fire ant colonies (Hymenoptera: Formicidae). Annals of the Entomological Society of America 79:723-726. 
Ridley M. 1993. Clutch size and mating frequency in parasitic Hymenoptera. American Naturalist 142:893-910.

Rinderer TE, Collins A, Brown M. 1983. Heritabilities and correlations of the honey bee: response to Nosema apis, longevity, and alarm response to isopentyl acetate. Apidologie 14:79-85.

Rinderer TE, Sylvester HA. 1978. Variation in response to Nosema apis, longevity, and hoarding behavior in a free-mating population of the honey bee. Annals of the Entomological Society of America 71:372-374.

Schmid-Hempel P. 1998. Parasites in Social Insects. Princeton University Press.

Sebastiani P, Solovieff N, Dewan AT, Walsh KM, Puca A, Hartley SW, Melista E, Andersen S, Dworkis D a, Wilk JB et al. 2012. Genetic signatures of exceptional longevity in humans. PloS ONE 7:e29848.

Silva-Matos E da, Garófalo C. 2000. Worker life tables, survivorship, and longevity in colonies of Bombus (Fervidobombus) atratus (Hymenoptera: Apidae). Revista de biología tropical 48:657-663.

Spradbery J. 1973. Wasps. An account of the biology and natural history of social and solitary wasps, with particular reference to those of the British Isles. Sidgwick \& Jackson Ltd.

Strassman JE. 1979. Honey Caches Help Female Paper Wasps (Polistes annularis) Survive Texas Winters. Science 204:207-9.

Strassmann J. 1981. Parasitoids, predators, and group size in the paper wasp, Polistes exclamans. Ecology 62:1225-1233.

Strassmann J. 1985. Worker mortality and the evolution of castes in the social wasp Polistes exclamans. Insectes sociaux 32:275-285.

Sumner S, Lucas E, Barker J, Isaac N. 2007. Radio-tagging technology reveals extreme nest-drifting behavior in a eusocial insect. Current Biology 17:140-5.

Tarpy DR, Keller JJ, Caren JR, Delaney D a. 2011. Experimentally induced variation in the physical reproductive potential and mating success in honey bee queens. Insectes Sociaux 58:569-574.

Tibbetts E, Reeve H. 2003. Benefits of foundress associations in the paper wasp Polistes dominulus: increased productivity and survival, but no assurance of fitness returns. Behavioral Ecology 14:510-514.

Torres V de O, Gianotti E, Antonialli-Jr W. 2013. Temporal Polyethism and Life Expectancy of Workers in the Eusocial Wasp Polistes canadensis canadensis Linnaeus (Hymenoptera: Vespidae). Sociobiology 60:107113.

Turillazzi S, West-Eberhard MJ. 1996. Natural History and Evolution of Paper-Wasps. Oxford University Press.

VanRaden PM, Klaaskate EJ. 1993. Genetic evaluation of length of productive life including predicted longevity of live cows. Journal of dairy science 76:2758-64. 
407 Vollema a R, Groen a F. 1996. Genetic parameters of longevity traits of an upgrading population of dairy cattle. $408 \quad$ Journal of dairy science 79:2261-7.

409 West-Eberhard MJ. 1969. The Social Biology of Polistine Wasps. Miscellaneous publications, Museum of $410 \quad$ Zoology, University of Michigan 140.

411 Wilson EO. 1971. The insect societies. Cambridge: Belknap Press of Cambridge University Press.

412 Wilson E. 1975. Sociobiology: The new synthesis. Harvard University Press.

413 
1

Captive housing of $P$. canadensis colonies:

A nest carton supported on reinforced celling with shade; B artificial planting; C ventilation;

$\mathbf{D}$ access hatch; $\mathbf{E}^{1}$ food provisions; $\mathbf{E}^{2}$ construction paper; $\mathbf{E}^{3}$ artificial planting; $\mathbf{E}^{4}$ liquid sugar cane; $\mathbf{E}^{5}$ distilled water.

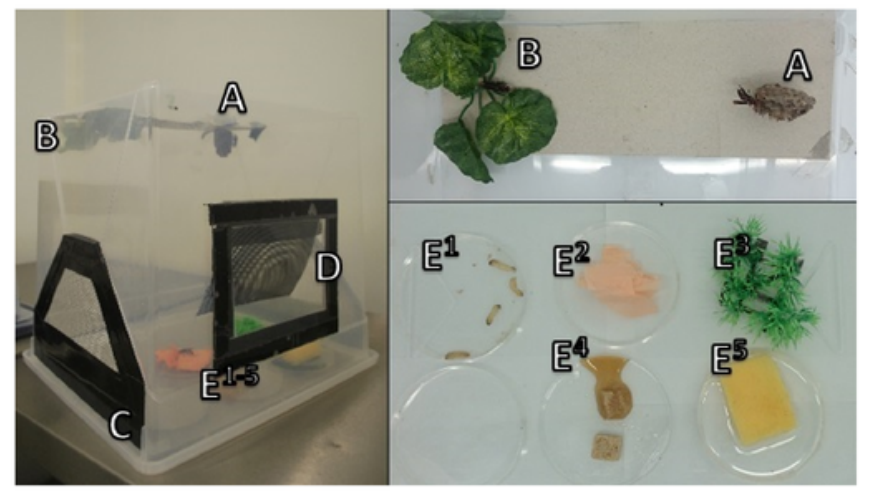


Survival details of seven colonies of $P$. canadensis over 450 days

Survival of adults in seven Polistes canadensis colonies shown as raw numbers (A) and proportions (B) over a period of 15 months post capture whilst maintained under laboratory conditions. Their longevity estimates of adult wasps for each colony as estimated by KaplanMeier survival analysis (C) with pairwise differences as calculated by the Breslow statistic shown by capped horizontal bars (D)

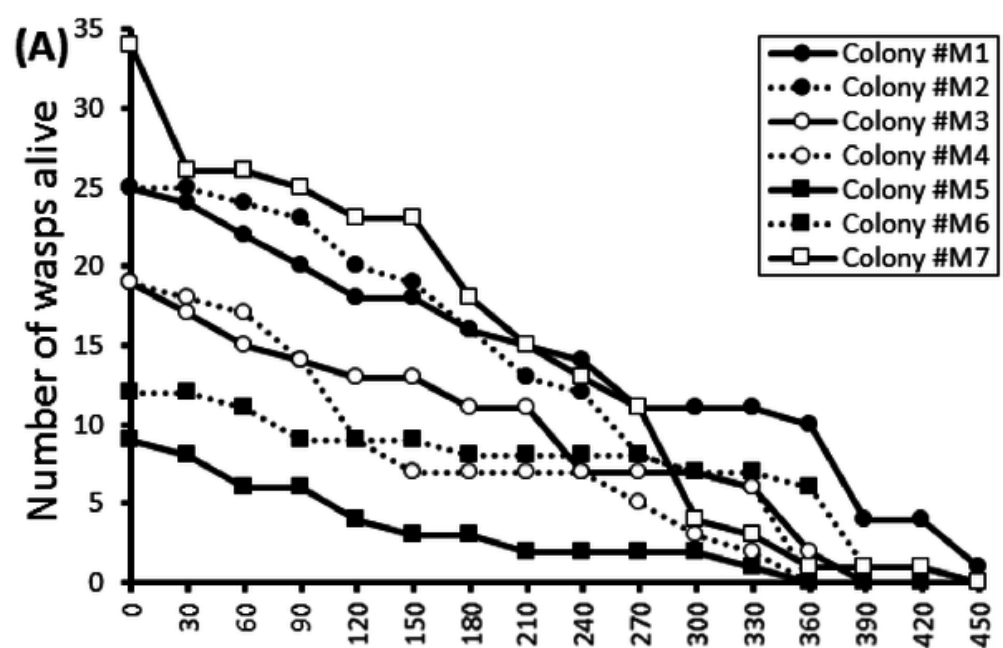

(C)

\begin{tabular}{|c|c|c|c|c|}
\hline \multirow{3}{*}{ Colony } & \multicolumn{4}{|c|}{ Mean $^{2}$} \\
\hline & \multirow{2}{*}{ Estimate } & \multirow{2}{*}{ Std. Error } & \multicolumn{2}{|c|}{ 95\% Confidence Interval } \\
\hline & & & Lower Bound & Upper Bound \\
\hline M6 & 260.01 & 41.34 & 178.98 & 341.04 \\
\hline M1 & 238.8 & 28.62 & 182.7 & 294.9 \\
\hline M2 & 207.6 & 19.2 & 169.95 & 245.25 \\
\hline M3 & 194.22 & 29.76 & 135.87 & 252.57 \\
\hline M7 & 167.64 & 20.52 & 127.44 & 207.84 \\
\hline M4 & $151.5 \mathrm{~g}$ & 24.96 & 102.63 & 200.52 \\
\hline M5 & 129.99 & 39.36 & 52.83 & 207.18 \\
\hline Overall & 193.86 & 10.5 & 173.25 & 214.44 \\
\hline
\end{tabular}
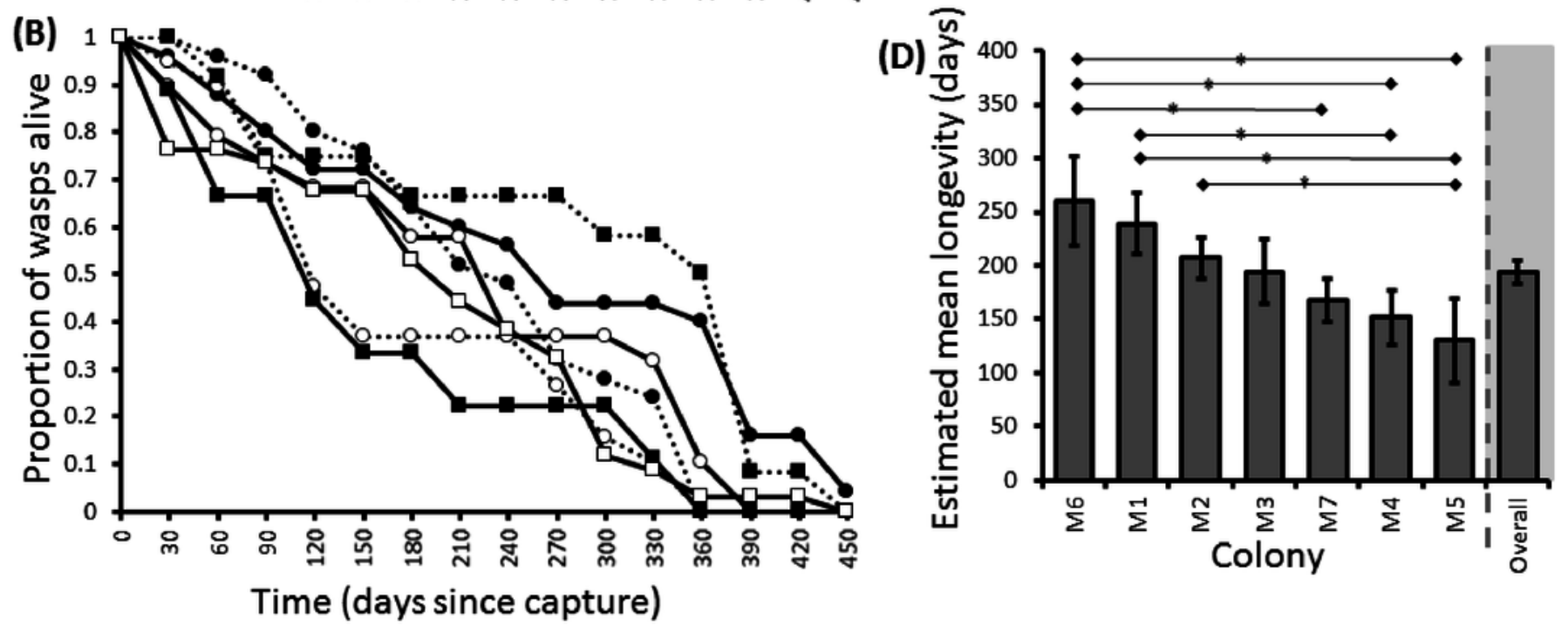
3

Mean longevity per colony against colony size

Correlations between colony size and mean longevity of adult $P$. canadensis when

maintained in original colony (A) or when manipulated into cohorts of varying size (B).

Standard error bars calculated by Kaplan-Meier model.

(A)

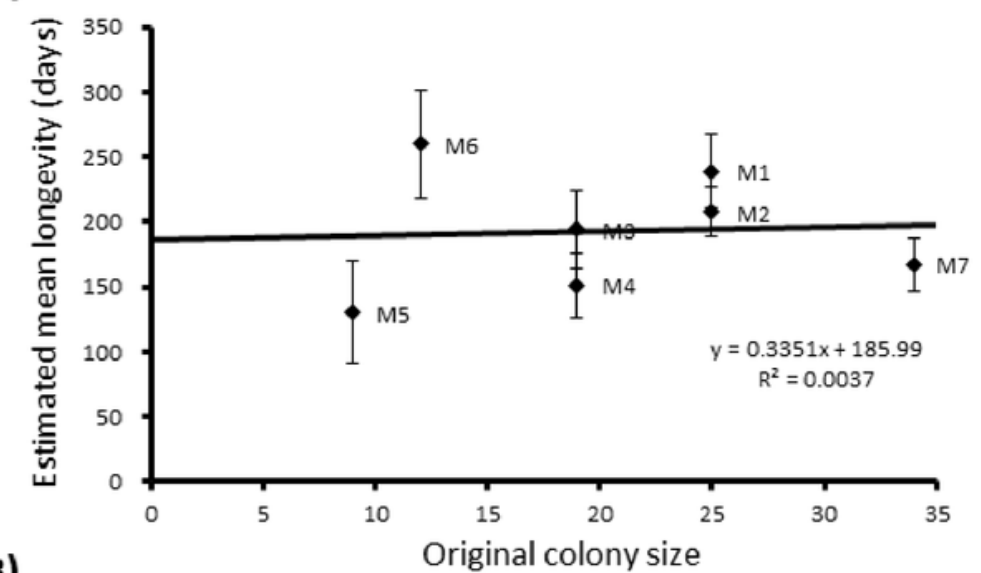

(B)

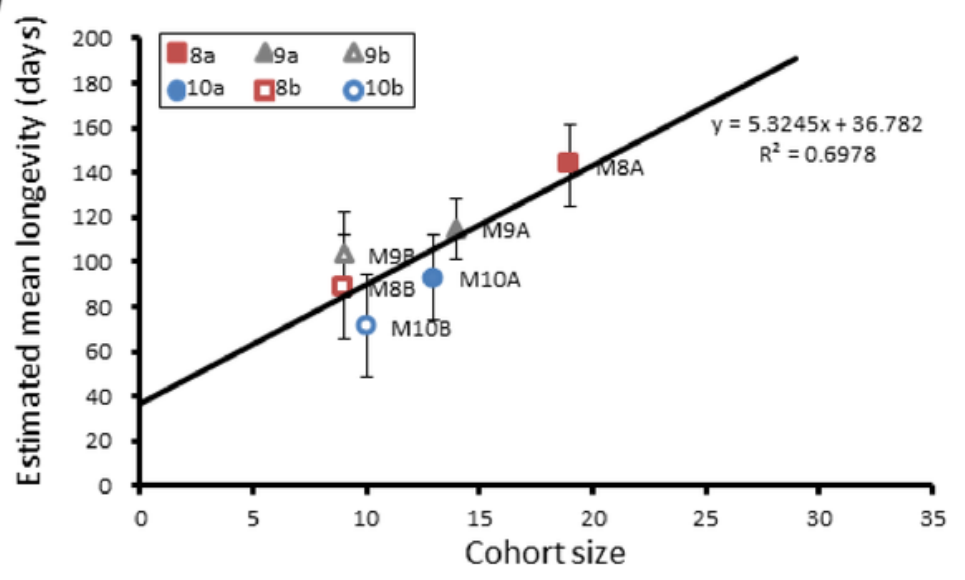


Survival details of three colonies of $P$. canadensis over 80 days

Survival of adults in three Polistes canadensis colonies (92 adults) shown as raw numbers (A) and proportions (B) over a period of 80 days post capture whilst maintained under laboratory conditions, along with the survival estimates for each colony as estimated by Kaplan-Meier survival analysis (C) Estimations used in C-D are limited to the largest survival time due to censorship. Standard error bars in (D) calculated by Kaplan-Meier model.

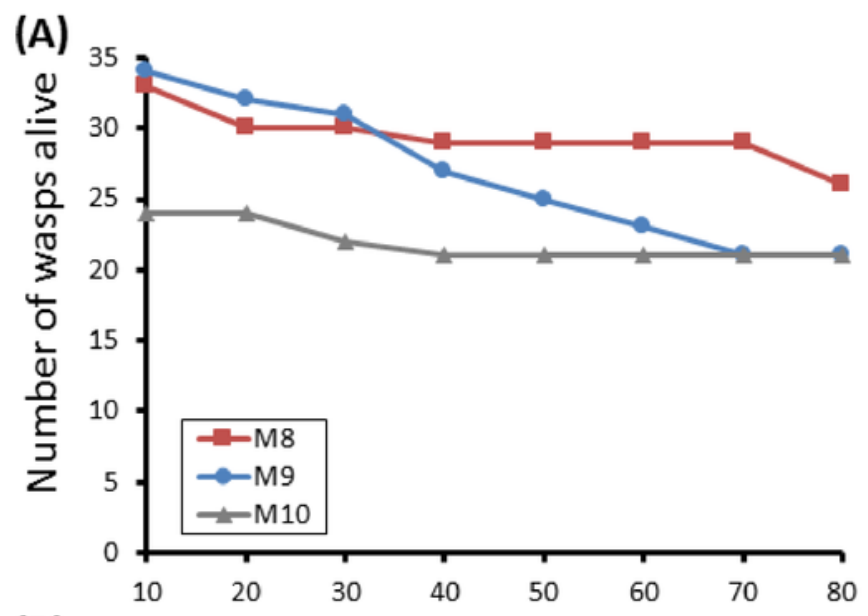

(B)

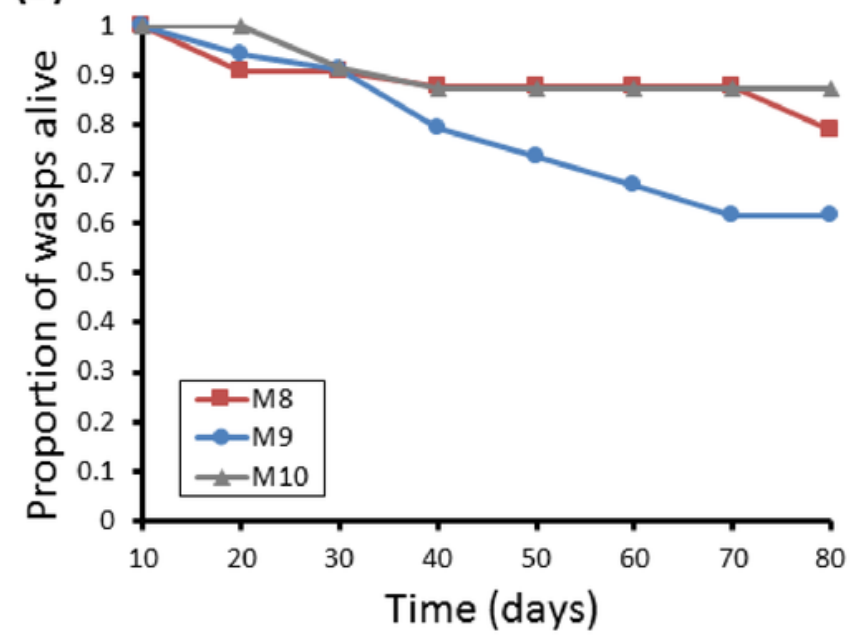

(C)

\begin{tabular}{|c|c|c|c|c|}
\hline \multirow{3}{*}{ Colony } & \multicolumn{4}{|c|}{ Mean ${ }^{a}$} \\
\hline & \multirow[b]{2}{*}{ Estimate } & \multirow[b]{2}{*}{$\begin{array}{l}\text { Std. } \\
\text { Error }\end{array}$} & \multicolumn{2}{|c|}{$95 \%$ Confidence Interval } \\
\hline & & & $\begin{array}{l}\text { Lower } \\
\text { Bound }\end{array}$ & Upper Bound \\
\hline M10 & 74.167 & 3.169 & 67.956 & 80.377 \\
\hline M8 & 71.471 & 3.829 & 63.967 & 78.975 \\
\hline M9 & 67.353 & 3.525 & 60.443 & 74.263 \\
\hline Overall & 70.652 & 2.064 & 66.606 & 74.698 \\
\hline
\end{tabular}

(D)

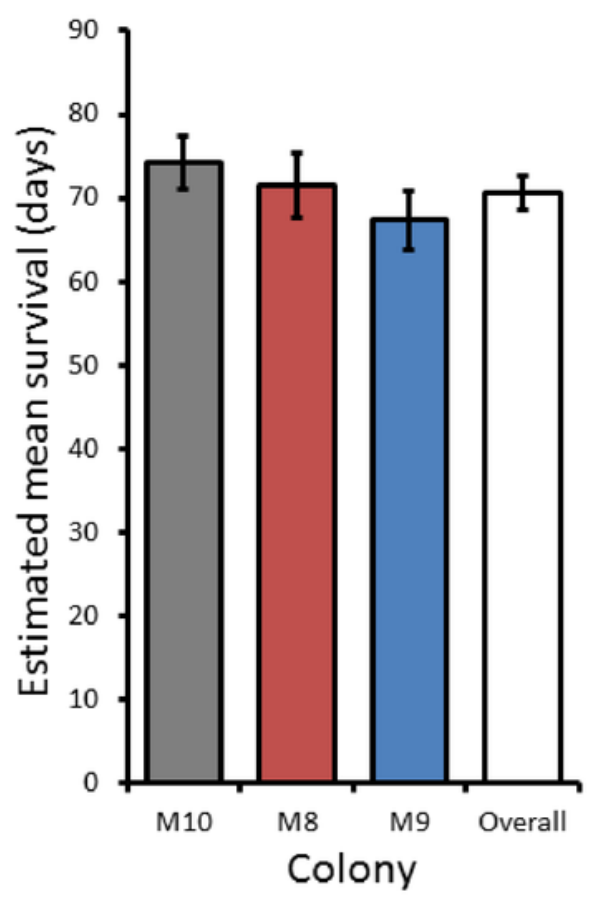




\section{5}

Survival details of six cohorts of $P$. canadensis wasps from 3 natal colonies

Survival of 72 adult Polistes canadensis in 6 conspecific groups split from 3 colonies, shown as raw numbers (A) and proportions (B) over a period of 220 days post split whilst maintained under laboratory conditions. The survival estimates of these as estimated by Kaplan-Meier survival analysis are shown (C) with pairwise differences as calculated by the Breslow statistic shown by capped horizontal bars (D)

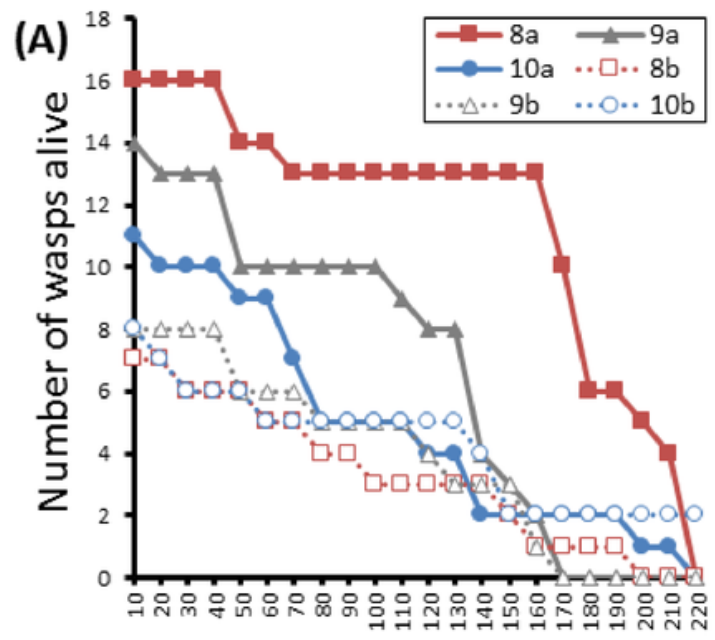

(C)

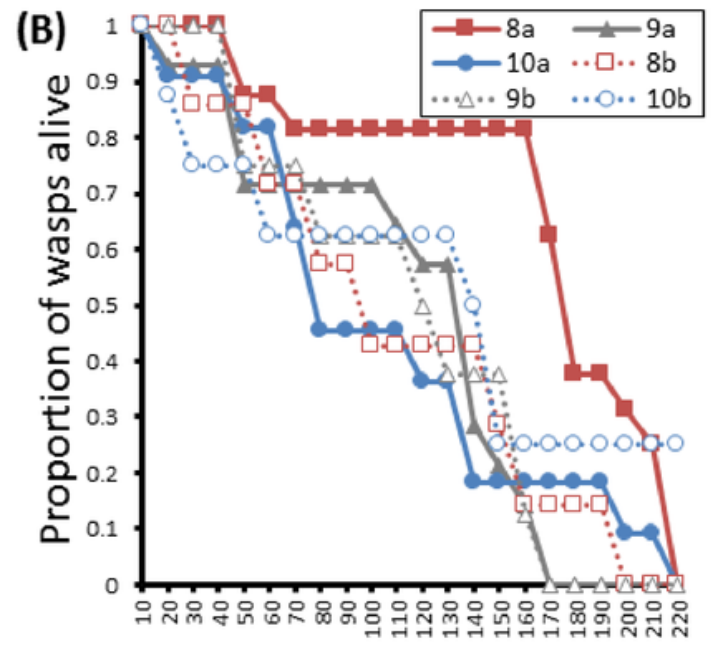

Time (days since split)

\begin{tabular}{|l|r|r|r|r|}
\hline \multirow{2}{*}{ Colony } & \multicolumn{4}{|c|}{ Mean $^{\text {a }}$} \\
\cline { 2 - 5 } & \multirow{2}{*}{ Estimate } & \multirow{2}{*}{ Std. Error } & 95\% Confidence Interval \\
\cline { 3 - 5 } & & & Lower Bound & Upper Bound \\
\hline M10A & 93.077 & 18.790 & 56.249 & 129.909 \\
\hline M10B & 71.250 & 22.791 & 26.580 & 115.929 \\
\hline M8A & 143.158 & 18.322 & 107.249 & 179.069 \\
\hline M8B & 88.889 & 23.009 & 43.809 & 133.969 \\
\hline M9A & 115.000 & 13.577 & 88.389 & 141.611 \\
\hline M9B & 103.333 & 19.293 & 65.519 & 141.149 \\
\hline Overall & 108.889 & 8.140 & 92.939 & 124.843 \\
\hline
\end{tabular}

(D)

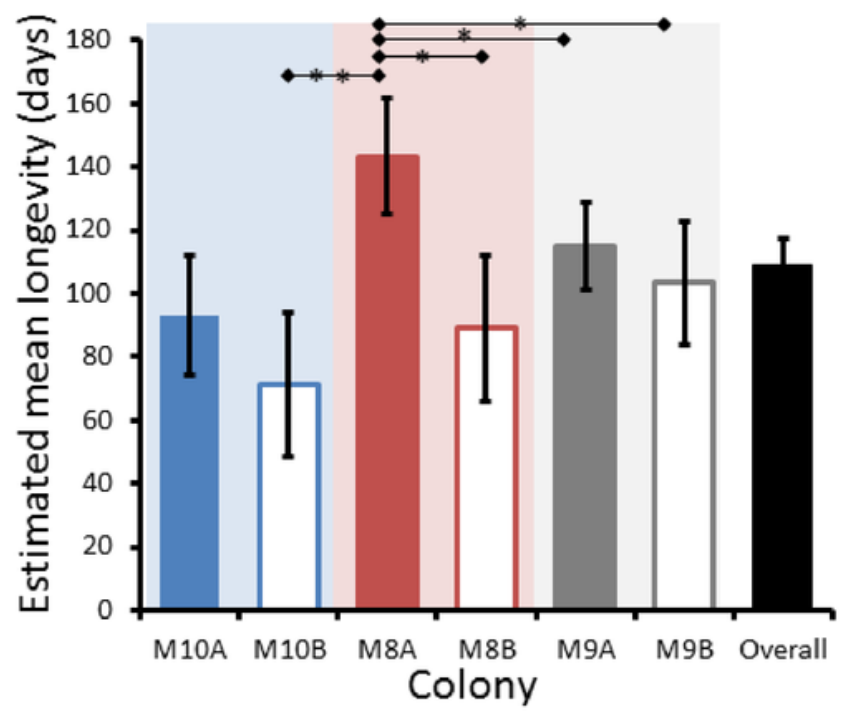




\section{6}

Comparative mean lifespans in ants, bees and wasps.

Comparison of lifespans in a selections of ants (A), bees (B) and all records of wasps (C), highlighting whether data is attained from wild (Black bars) or assisted (grey bars) colonies with unknowns also included (grey bars). Queen lifespans in minimum age, as most studies/literature start from colony creation. Data compiled from the result of this study ( above column) and those found following literature search (Pardi, 1948; Michener, 1969; West-Eberhard, 1969; Matsuura, 1971; Wilson, 1971; Spradbery, 1973; Miyano, 1980; Haskins \& Haskins, 1980; Akre, 1982; Strassmann, 1985; Goldblatt \& Fell, 1987; Dazhi \& Yunzhen, 1989; Hölldobler \& Wilson, 1990; Pamilo, 1991; O’Donnell \& Jeanne, 1992a; Giannotti \& Machado, 1994; Keller, 1998; Silva-Matos \& Garófalo, 2000; Page Jr \& Peng, 2001; Gamboa, Greig \& Thom, 2002; Jemielity et al., 2005; Hurd, Jeanne \& Nordheim, 2007; Archer, 2012; Giannotti, 2012; Torres, Gianotti \& Antonialli-Jr, 2013; Halcroft, Haigh \& Spooner-Hart, 2013) 
(A) Ants

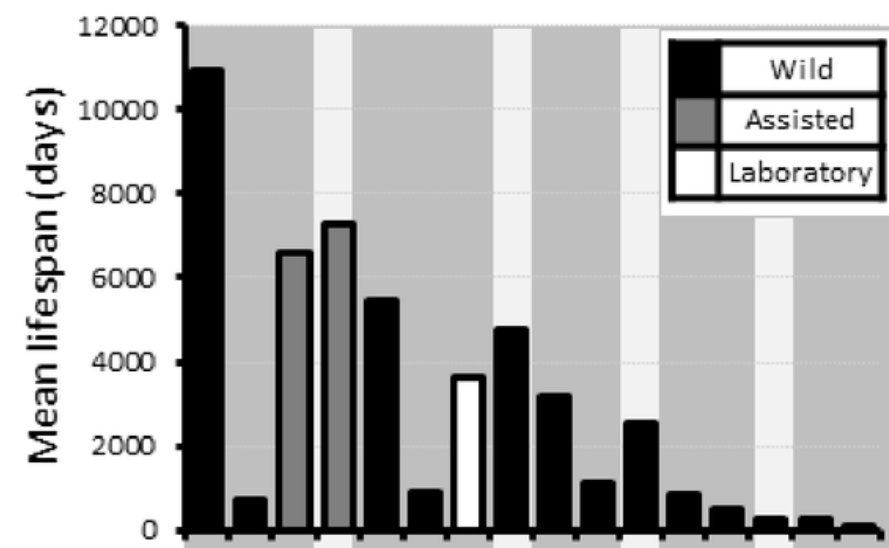

2.

$\bar{E} \bar{E}$

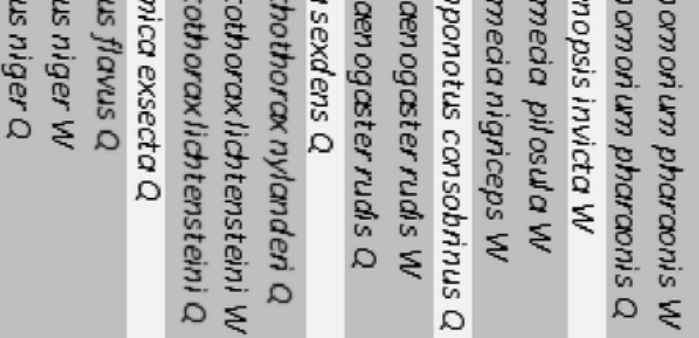

Genus and species

\section{(B) Bees}

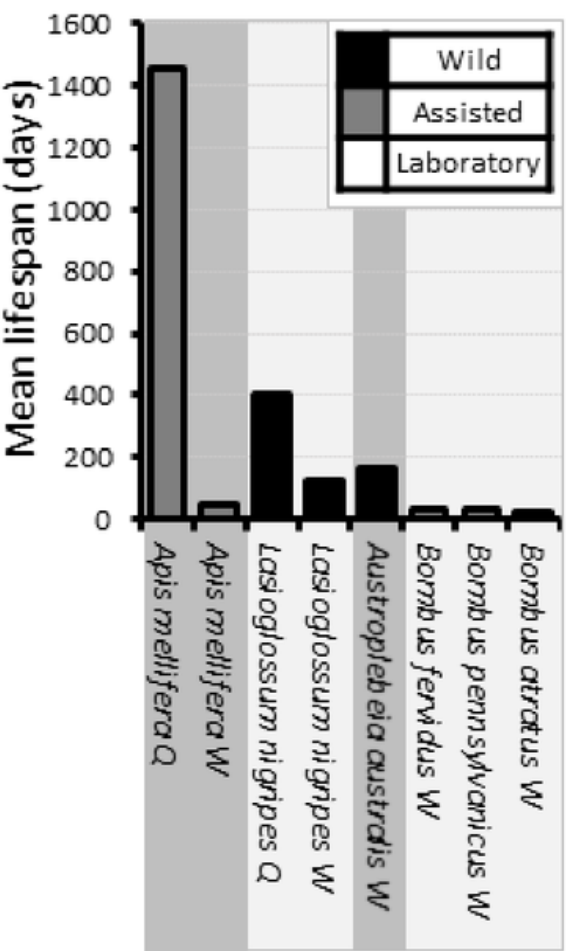

Genus and species

\section{(C) Wasps}

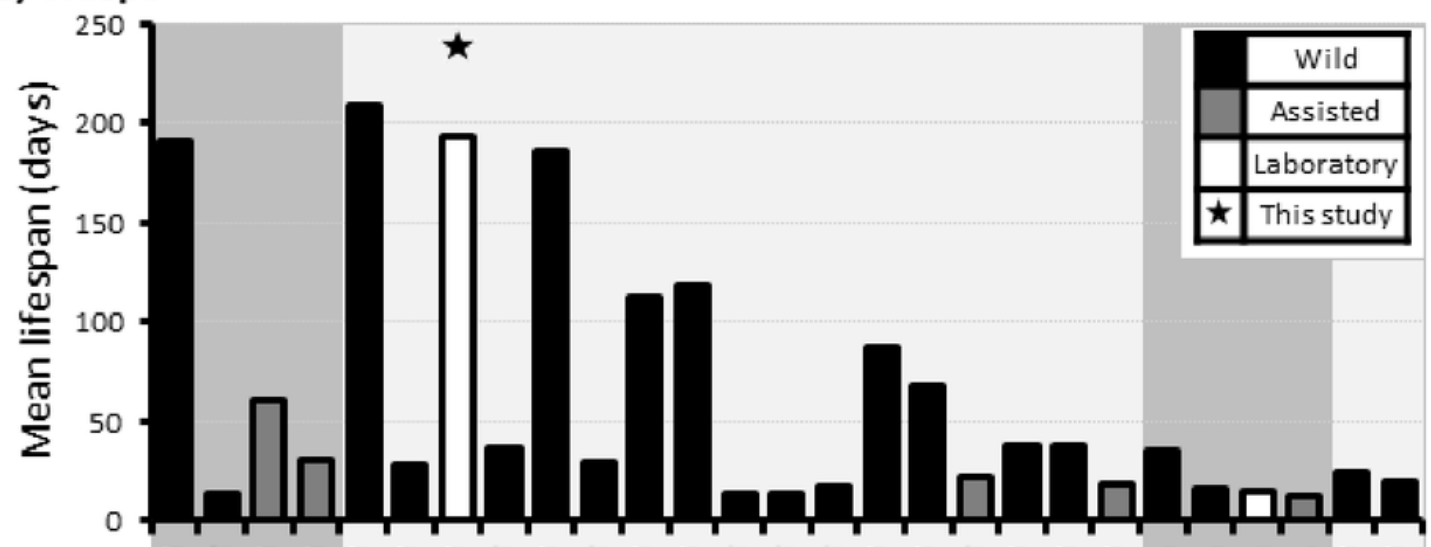

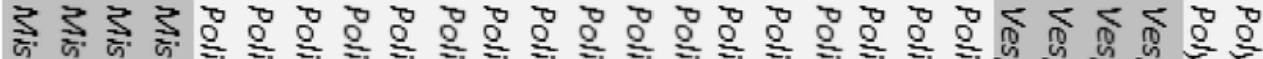

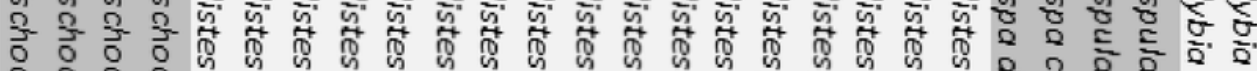

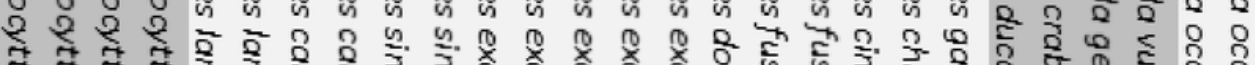

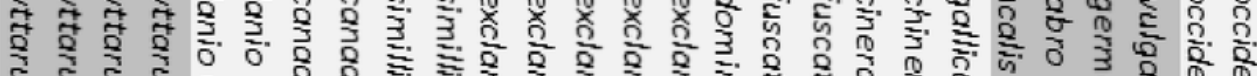

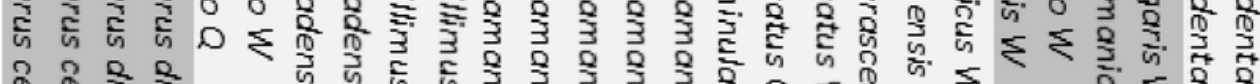

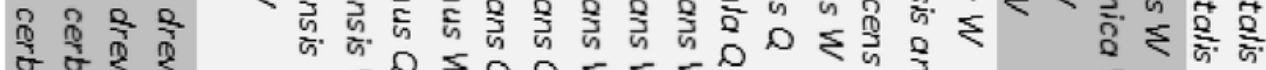
का हो की

$0 \sum$

us

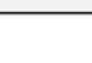

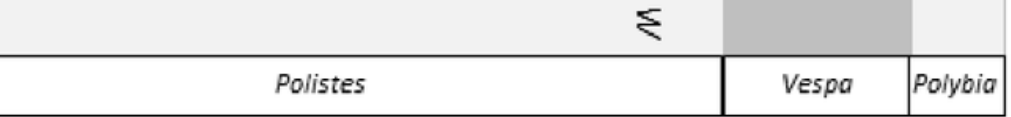

